\title{
MARGINALIDADE E REEDUCAÇÃO DE MENORES EM PORTUGAL: A COLÓNIA DE VILA FERNANDO (1880-1940)
}

\author{
Helder Manuel Guerra Henriques \\ Instituto Politécnico de Portalegre - ESEP
}

Recibido: 18/9/2014

Aceptado: $24 / 11 / 2014$

\begin{abstract}
In this paper we seek to discuss the process of regeneration of marginal minors in Portugal in the early decades of the twentieth century. For this purpose, we take as example the Agricultural / Correctional Colony of Vila Fernando (Elvas, Portugal). We argue that the act of reeducation interned children went there primarily for work, the discipline and moral training of individuals. The ultimate goal was the return of the children with social utility. We anchored the work in the History and Philosophy of Education, we use a large document corpus and a methodology based on historical criticism.
\end{abstract}

KEYWORDS: Minor; Marginal; Reeducation; Abnormal; Colony of Vila Fernando.

RESUMEN: En este texto procuramos discutir el proceso de regeneración de menores marginales en Portugal en las primeras décadas del Siglo XX. Para el efecto, tomamos como ejemplo la Colonia Agrícola/Correccional de Vila Fernando (Elvas, Portugal). Defendemos que el acto reeducativo de los menores allí internados pasaba esencialmente por el trabajo, por la disciplina y por la formación moral de los individuos. El objetivo mayor era la devolución de los menores con utilidad social. Anclamos el trabajo en la Historia y Filosofía de la Educación, utilizamos un corpus documental amplio y una metodología asentada en la crítica histórica.

PALABRAS CLAVE: Menor; Marginal; Reeducación; Anormal; Colonia de Vila Fernando.

\section{INTRODUÇÃO}

$\mathrm{Na}$ atualidade a preocupação com a infância, em sentido lado, é uma evidência. Essa preocupação aumenta quando se trata de crianças e jovens em situação de risco. $\mathrm{O}$ interesse por este tipo de crianças e/ou jovens foi crescendo ao longo do século XX alimentado por uma razão de Estado que procurou normalizar este público utilizando para o efeito, e em alguns casos, instituições espe- 
cializadas (Reformatórios; Institutos médico-Pedagógicos; Casas para a Infância desvalida; Colónias Correcionais, etc...) cujo principal objetivo era recolhê-las e reabilitá-las para a vida em sociedade. José Ortega Esteban a propósito de uma instituição desta natureza escreveu a partir da sua experiência, no final da ditadura Franquista, que:

"Los reformatorios vienen a ser los retretes donde la sociedad capitalista defeca. Estos lugares nunca han estado a la luz, oscuros, retirados, ocultos, dissimulados...Sus olores han sido soportados por las clases más empobrecidas del Pueblo, hijos de famílias rotas y desheredadas de la fortuna. A revolver un poco este «detritus» para que todos, pues todos somos responsables, huelan su parte (...)"1.

Este testemunho é bastante ilustrador de uma realidade que necessariamente foi evoluindo para outros patamares não deixando, no entanto, de continuar a ter atualidade e a retratar, em parte, algumas circunstâncias institucionais. Interessados por esta matéria quisemos olhar para o passado e analisar uma instituição portuguesa cujo maior objetivo era regenerar os seus internados. Estamos a referir-nos à Colónia de Vila Fernando, localizada no distrito de Portalegre. Assim, procuramos colocar algumas questões orientadoras para a construção deste trabalho:

Porque e onde surgiu a Colónia de Vila Fernando? Qual era a sua principal missão? De que modo procedia à normalização dos indivíduos internados? Que lugar ocupava a educação no ato reeducativo?

Estas questões, embora articuladas entre si, constituem o referencial que esteve presente ao longo do trabalho num arco temporal associado à primeira metade de novecentos.

Do ponto de vista teórico encontramos o nosso vínculo na História e filosofia da educação com especial destaque para os processos relacionados com a normalização / anormalização dos indivíduos ${ }^{2}$.

\footnotetext{
${ }^{1}$ ESTEBAN, J. O. (2010). Delincuencia, reformatório y educación liberadora. Salamanca: Amaru ediciones, pp. 47 [1 ${ }^{\mathrm{a}}$ ed. 1978].

${ }^{2}$ Entre outros destacamos a importância dos seguintes trabalhos:

FOUCAULT, M. (2001). Los Anormales. Madrid: Akal Ediciones;

FOUCAULT, M. (2006). Vigiar e Punir - História da Violência nas Prisões, $31^{\mathrm{a}}$ edição, Petrópolis: Editora Vozes.;

FOUCAULT, M. (2006). Estratégia, Poder - Saber, $2^{\mathrm{a}}$ ed., col. Ditos \& Escritos IV, Rio de Janeiro: Forense Universitária.

DEL CURA GONZALEZ, M. (2011). Medicina y Pedagogía - La Construccion de la Categoria «Infância Anormal» en España (1900-1939), Madrid: Consejo Superior de Investigaciones Científicas; etc.
} 
Do ponto de vista empírico recorremos a um corpus documental que podemos dividir em dois núcleos: por um lado, utilizamos a legislação publicada em Portugal sobre a instituição que tomamos como referência na nossa análise; por outro lado, utilizamos fontes documentais que permitem retratar o quotidiano institucional destacando-se, entre outros, relatórios, catálogos de exposições, periódicos e iconografia (publicada). A metodologia utilizada baseia-se na crítica histórica uma vez que este método permite colocar em crise as fontes, dialogar com as questões orientadoras e com os autores de referência que mobilizamos para este texto. Iniciamos o estudo com uma revisão da literatura - o Estado da Arte - transitando, depois, para a identificação, recolha e leitura do corpus documental. Da conjugação entre os referenciais teóricos e as fontes documentais procedemos à análise crítica, validando as fontes, chegando posteriormente à construção do texto.

$\mathrm{O}$ trabalho encontra-se dividido em três partes fundamentais. Na primeira parte, discutimos a problemática da marginalidade/anormalidade na relação com a Infância. Na segunda parte, procuramos caraterizar o contexto institucional que serve de arena para a terceira parte. Aqui, discutimos o processo de regeneração dos menores internados na instituição ao longo da primeira metade de novecentos, com especial destaque para as primeiras décadas.

Defendemos que o processo de regeneração do individuo transita gradualmente de uma conceção essencialmente punitiva para uma conceção onde a educação se torna o principal aliado no ato reeducativo.

\section{A «INFÂNCIA MARGINAL»: ESBOÇO CONCEPTUAL}

A infância, ao longo da modernidade, foi interpretada por diversos especialistas (médicos, psiquiatras, pedagogos, etc.) e saberes que atribuíram centralidade a esta etapa da vida contribuindo para um maior (re) conhecimento sobre as crianças e/ou jovens. Esta etapa foi considerada fundamental na construção do indivíduo e da sociedade dado que é na infância que se joga a construção do adulto socialmente ajustado. A infância tornou-se matéria de interesse público na medida em que o seu governo, de acordo com o entendimento da época, potenciava a ordem social e o futuro da nação ${ }^{3}$.

A Escola, ao serviço do Estado-Nação em processo de emergência, constituiu o mecanismo ideal para formar as novas gerações. No século XVII Coménio apontava para esta necessidade quando defendia o projeto de uma educação universal do Homem "(...)em que todos sejam educados em todas as coisas e

${ }^{3}$ Cf. ROSE, N. (1999). Governing the soul: the shaping of the private self. London: Free Association Books. 
totalmente"4. Esta ideia ganhou substância com a edificação de um sistema educativo gradualmente obrigatório, dirigido pelo Estado, aglutinador desta etapa da vida procurando (en)formar aqueles que eram considerados o futuro da nação. Como defende Jorge Ramos do Ó:

"Os sistemas estatais de ensino foram sendo (...) constituídos de acordo com a regra de governamentalidade: o treino moral da população jovem fez-se tendo em vista o objectivo mais geral do aumento da força e prosperidade do Estado, mas teve pressuposta a reivindicação do bem-estar de cada um dos cidadãos". 5

O Estado através da instituição escolar, em conjunto com diferentes especialistas ligados a um saber psicológico emergente, ampliou este entendimento colocando a Escola como elemento normalizador da infância. Este procedimento tornou visível outros tipos de "infância": as crianças «marginais».

A marginalidade deve ser entendida como "(...) um produto histórico" que se exprime por se encontrar à margem de qualquer atitude e/ou comportamento socialmente aceite. De acordo com António Gomes Ferreira "a marginalidade é

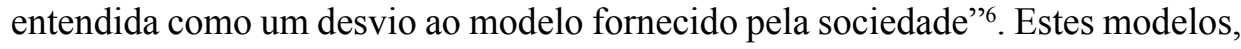
a que se refere o autor, constituem os referenciais construtores da normalidade/ anormalidade. Assim, consideramos, tal como Jeroen Dekker, que a marginalidade e/ou anormalidade são uma abstração que se concretiza quando comportamentos e atitudes, variáveis no espaço e no tempo, são incorporados por um conjunto de indivíduos ${ }^{7}$ permitindo definir de que lado da "margem" se encontram.

Ao longo do século XIX tornou-se mais visível a existência de um conjunto de crianças e jovens que não correspondiam aquilo que a sociedade pretendia para elas/es. Em Portugal, em tempo de industrialização e urbanização, era comum encontrar crianças que não estavam devidamente alimentadas, cujo meio

${ }^{4}$ COMÉNIO, J.A. ( trad. 1971). Pampaedia (Educação Universal). Coimbra: Faculdade de Letras da Universidade de Coimbra, p. 37.

${ }^{5}$ Ó, J.R. (2009). “"A criança problema» e o seu governo em Portugal e no Brasil” In Ó, J.R \& CARVALHO, L.M. (Orgs.). Emergência e Circulação do Conhecimento Psicopedagógico Moderno (1880-1960). Lisboa: Educa, pp. 35

${ }^{6}$ FERREIRA, A. G. \& LIMA, C.C. (2004). "Menores em risco social e delinquentes no século XIX e princípios do século XX à luz da legislação portuguesa" In FARIA FILHO, L.M. (org.), A Infância e a sua Educação - materiais, práticas e representações (Portugal - Brasil), Belo Horizonte: Autentica, pp. 84 e 85.

${ }^{7}$ DEKKER, J.J.H. (1990). "The fragile relation between normality and marginality. Marginality and Institutionalization in the history of education”. Paedagógica Historica, XXVI, Gent. 
familiar era moralmente duvidoso ou onde o meio social era propicio ao vicio, à ociosidade ou ao crime ${ }^{8}$. A este propósito Maria R. Tomé é esclarecedora:

"O problema da infância pobre, maltratada, vadia, mendiga, anormal, indisciplinada e delinquente era uma afronta à ordem social e corria pelo mundo desde o século XIX, por via da tomada de consciência, quer social quer judicial, que a defesa social como princípio de justiça exigia medidas "prevenção" à inadaptação social, pela conjugação de medidas de assistência com medidas de prevenção criminal"".

O Estado, interessado na construção de uma sociedade "dócil", tentou encontrar soluções para controlar, corrigir e regenerar os indivíduos moralmente duvidosos. Estes constituíam um perigo para a restante sociedade e, por isso, era necessário compreende-los, estudá-los e vigiá-los. Era, portanto, da maior importância preservar o bem estar das gerações mais novas, proporcionando-lhes as condições físicas e psicológicas possíveis e necessárias ao seu desenvolvimento "normal" evitando contágios com aqueles que se encontravam "à margem".

Ilustração 1. Gabinete médico da Colónia de Vila Fernando (primeira metade do século $X X)^{10}$.

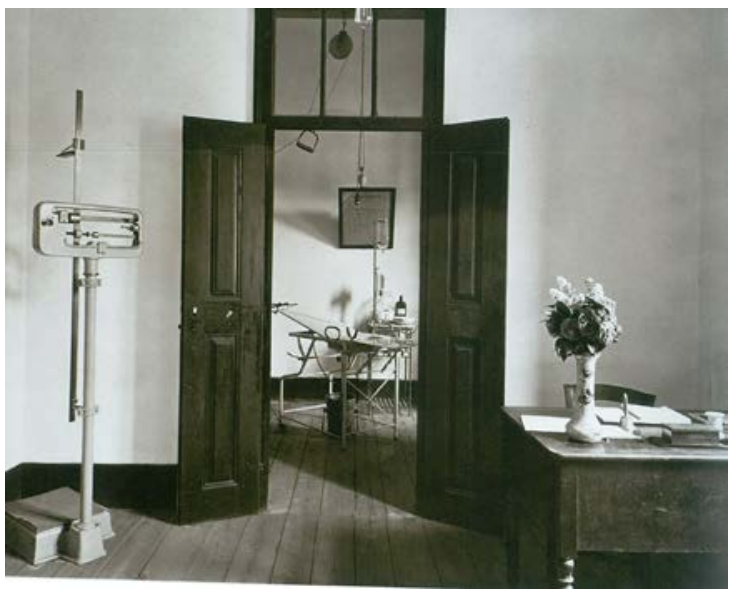

\footnotetext{
${ }^{8}$ Cf. DEL CURA GONZALEZ, M. (2012). Medicina y Pedagogía - La Construccion de la Categoria «Infância Anormal» en España (1900-1939). Madrid: Consejo Superior de Investigaciones Cientificas.

${ }^{9}$ TOMÉ, M. R. (2010). A cidadania infantil na Primeira República e a tutoria da infância. A criação da Tutoria de Coimbra e do refúgio anexo. Revista de História da Sociedade e da Cultura. Vol. 10 (2010) T. 2, pp. 481.

${ }^{10}$ Imagem extraída de BANDEIRA, F. (2009). et al. Arquitectura de serviços públicos em Portugal: os internatos na justiça de menores (1871-1978). Lisboa: DGRS/IHRU, pp. 270.
} 
Foi à luz deste contexto que os reformadores sociais denunciaram os problemas, associados às crianças e jovens que fugiam à norma e que por isso era necessário corrigir e/ou regenerar. Gradualmente a arena escolar foi sendo preenchida por um conjunto de experts que se ocupavam das gerações mais novas e que tentavam identificar esses comportamentos e atitudes errantes. A Escola surgiu, deste modo, como parte do projeto sociopolítico do Estado que procurou, no detalhe, identificar e classificar os indivíduos partindo do pressuposto que estava a defender a sociedade:

"Os fins educativos estão portanto estruturalmente associados a dinâmicas sociais tão diversas como as do ajustamento social, do castigo, da produtividade, da vitória. Foi desta sorte que as crianças começaram a ser igualmente um dos alvos privilegiados dos programas de individualização levados a cabo pelos experts do particular, os psicólogos e os pedagogos"11.

A associação entre indivíduos anormais/marginais e ociosidade ou crime era uma evidência no Portugal de oitocentos. Associava-se o jovem marginal àquele que não possuía qualquer atividade, ofício ou profissão, remetendo-o para a ideia de "escândalo", de perturbação do sossego público, da ordem pública e, por isso, eram rotulados como "inimigos da nossa segurança e propriedade" 12 .

Alfredo Veiga-Neto e Guilherme Castelo Branco afirmam que o governo dos indivíduos passava essencialmente pelos especialistas capazes de identificar a anormalidade/ marginalidade. Este processo de identificação passou pela criação de instrumentos de avaliação capazes de tornar visíveis os defeitos ou os hábitos e comportamentos errantes definindo o papel dos especialistas do seguinte modo:

"O seu trabalho [dos experts] disciplinar sobre a idiossincrasia consolidouse nos inúmeros registos criados para classificar, categorizar e calibrar as aptidões e as peculariedades das crianças em risco, a ponto de uma das mais criativas novidades do século XIX, e à qual as autoridades dariam a mais ampla visibilidade, ter sido a fixação, por um investigador brasileiro, do conceito de criança-problema [perigosa]"13.

Identificados os problemas da ordem do desvio, o caminho a seguir pelo Estado deveria ser o de encontrar uma forma de recolher e corrigir os indivíduos

\footnotetext{
${ }^{11}$ Ó, J.R. (2009). “"A criança problema» e o seu governo em Portugal e no Brasil” In Ó, J.R \& CARVALHO, L.M. (Orgs.). Emergência e Circulação do Conhecimento Psicopedagógico Moderno (1880-1960). Lisboa: Educa, pp. 34.

${ }^{12}$ Debates Parlamentares. Câmara dos Senhores Deputados, 1855: pp. 234.

${ }^{13}$ CASTELO BRANCO, G. \& VEIGA-NETO, A. (2011). Foucault: filosofia e política, Belo Horizonte: Autentica Editora, pp. 191.
} 
perigosos. É esclarecedor o testemunho encontrado num dos debates da Câmara dos Senhores Deputados, em 1880, sobre esta matéria:

"As difficuldades em que se encontra o governo todas as vezes que tem de dar destino aos muitos rapazes vadios, que frequentemente são postos á sua disposição pelo poder judicial, tem feito lembrar a necessidade de crear um estabelecimento onde aquelles infelizes alcancem a educação que lhes falta, e adquiram a moralidade e os habitos de trabalho, cuja ausência os encaminha á vagabundagem, e não poucas vezes ao crime"14.

A ociosidade, a mendicidade, a vadiagem constituíam fatores que poderiam conduzir as crianças e/ou jovens à marginalidade. A recomendação para combater este problema social passava pela criação de instituições que educassem, moralizassem e incutissem hábitos de trabalho aos menores marginais.

Ao Estado coube o papel de tentar criar esses mecanismos capazes de solucionar o problema que estes indivíduos podiam constituir para a sociedade no seu todo. Para o efeito, desenvolveu um conjunto de medidas que passavam por uma maior capacidade de regulação e controle social através da criação de contextos técnico-institucionais específicos onde se podia trabalhar a "qualidade" da criança e/ou jovem e promover o seu ajustamento. No fundo, pretendia-se a apropriação do corpo dos indivíduos, através do seu internamento, para moldar moralmente a sua alma.

É uma gestão moral dos indivíduos que se encontra em causa. Mitchell Dean, numa aproximação ao pensamento teórico de Michel Foucault, fala-nos na importância de governar os indivíduos através da "condução da conduta" por via de uma racionalidade calculada e utilizando técnicas e conhecimentos científicos diversos que procuravam combater a anormalidade ${ }^{15}$. Este combate é evidenciado em diploma publicado em 1901 quando podemos ler o seguinte:

"Questão complexa, como nenhuma outra, tem pontos de vista diversos para os cultores de todas as sciencias. É ella de tal complexidade que, para a resolver, se congregam, num mesmo esforço, o pedagogo, o jurisconsulto, o médico, o agricultor e o philanthropo" ${ }^{16}$.

A congregação de esforços, de saberes, avaliações, racionalidades procurando compreender os indivíduos marginais constituía a melhor estratégia para enfrentar o problema da marginalidade que se poderia tornar uma verdadeira

\footnotetext{
${ }^{14}$ Debates Parlamentares. Câmara dos Senhores Deputados, 1880: pp. 2009.

${ }^{15}$ DEAN, M. (1999). Governmentality: Power and rule in Modern Society. Londres: Sage, pp. 209.

${ }^{16}$ Diário do Governo, no 184, 29 de Agosto, pp. 376.
} 
ameaça socioeconómica e moral. Era imperativo agir sobre o individuo perigoso, compreendê-lo, conquistá-lo e "conduzir a sua conduta".

Para Ana Laura Lima esta ideia assume um duplo significado: por um lado, conduzir "tanto pode ser levar os outros a agir de determinada maneira, empregando-se para isso métodos mais ou menos coercitivos, como pode significar o controle das próprias atitudes num espaço de possibilidades relativamente abertas"17. Este duplo significado pode ser objetivado nos contextos técnico-institucionais criados em Portugal no final de oitocentos onde se puderam congregar esforços no processo de recuperação/regeneração dos indivíduos que constituíam um perigo para a sociedade. Exemplo do que acabamos de referir foi a Escola Agrícola de Vila Fernando que representou um modelo correcional e educativo cujo principal objetivo era vigiar, corrigir e regenerar indivíduos perigosos encaminhados, essencialmente, pelo poder judicial.

\section{A ESCOLA AGRÍCOLA DE VILA FERNANDO: O COMEÇO DE UMA LONGA HISTÓRIA}

A Escola Agrícola de Vila Fernando foi instituída em 1880, inspirada nas suas congéneres francesas. Esta instituição foi a primeira em Portugal, de matriz rural, cujo grande objetivo era corrigir e educar indivíduos menores que podiam constituir um perigo para a sociedade (vadios, mendigos, desvalidos e desobedientes).

A localização escolhida para a sua implementação foi o Alto Alentejo, no distrito de Portalegre e concelho de Elvas (Vila Fernando) (junto à fronteira com Espanha). O espaço de referência foi a herdade de Vila Fernando, com cerca de 800 hectares, com vários locais arborizados. Esta localização correspondia a um duplo interesse: por um lado, encontrava-se afastado dos grandes núcleos urbanos ${ }^{18}$; por outro lado, a instituição e os seus internados podiam contribuir para o povoamento do Alentejo, quando devidamente recuperados os indivíduos.

\footnotetext{
${ }^{17}$ LIMA, A. L.G. (2006). O espectro da irregularidade ronda o aluno. Tese de doutoramento. São Paulo, Brasil, pp. 26.

${ }^{18}$ SANTOLARIA SIERRA, F. F. (2009). "El campo educador. El retorno a la tierra y al hogar como respuesta a la infancia en riesgo social: algunas notas históricas (siglos XIX-XX)". In El largo camino hacia una educación inclusiva: la educación especial y social del siglo XIX a nuestros días: XV Coloquio de Historia de la Educación, Pamplona-Iruñea, 29, 30 de junio y 1 de julio de 2009 / coord. por María Reyes Berruezo Albéniz, Susana Conejero López, Vol. 2, págs. 357-370.
} 
Os primeiros trabalhos foram dirigidos pelo Engenheiro João Veríssimo Mendes Guerreiro que criou o projeto, realizando-se o inicio dos trabalhos dois anos depois (1882) da publicação da lei que autorizou a sua criação. A preocupação com o avançar dos trabalhos é evidenciada pelo Rei Dom Carlos quando fez publicar uma carta de lei onde concedia “(...) á commissão administrativa da escola agrícola de Villa Fernando o despacho, livre dos direitos aduaneiros, de machinas e utensilios que adquirir para o serviço das officinas do mesmo estabelecimento"19. Esta indicação manifesta a relevância do projeto para a tentativa de resolução do problema social que constituíam os menores marginais, apontando já para a importância da reeducação dos menores pelo trabalho.

Ilustração 2. Vista aérea da Colónia Correcional de Vila Fernando (Anos 30) ${ }^{20}$.

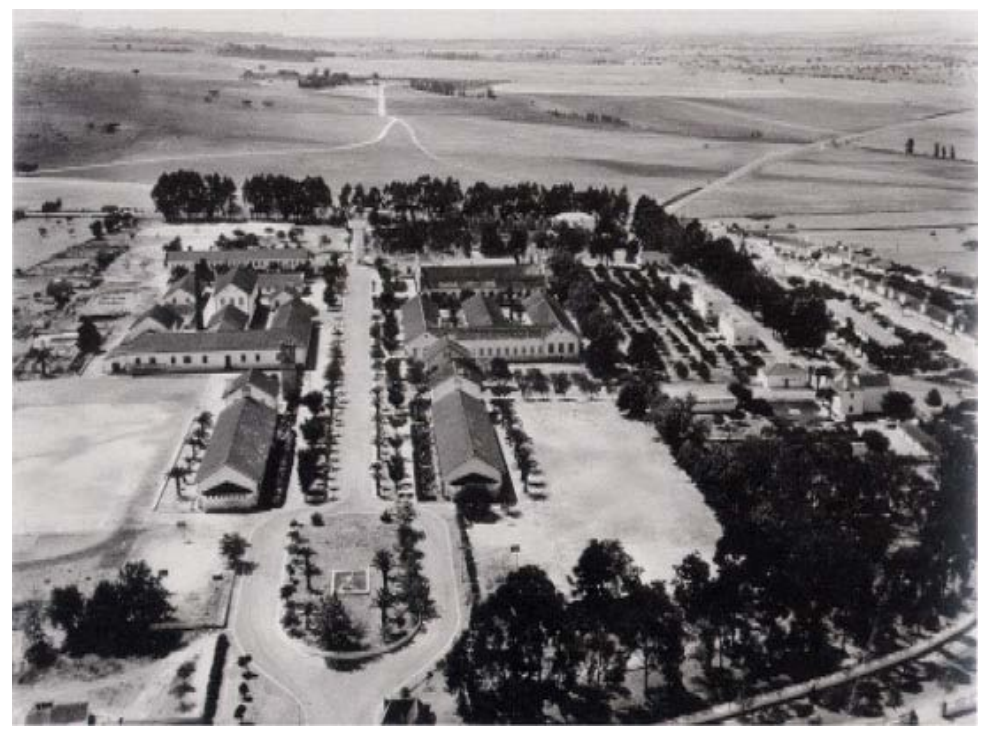

Em 1894 foi estabelecido o quadro de pessoal, e os respetivos vencimentos, que haveria de fazer parte da instituição, atribuindo, o governo, plenos poderes para a comissão administrativa nomear provisoriamente os elementos em cada uma das categorias apresentadas na tabela 1.

\footnotetext{
${ }^{19}$ Diário do Governo, Ministério dos Negócios do Reino, nº 160 de 22 de julho de 1891.

${ }^{20}$ AGAREZ, R. (2008). A Escola Agrícola de Reforma em Vila Fernando, 1881-1908 - Programa, projecto e obra da primeira colónia correcional portuguesa. Monumentos. 28, Dezembro, pp.164.
} 
Tabela 1. Mapa provisório de pessoal da Escola Agrícola de Vila Fernando (1894).

\begin{tabular}{|c|c|}
\hline \multicolumn{2}{|c|}{ Mapa de Pessoal da Escola Agrícola de Vila Fernand } \\
\hline $\begin{array}{l}1 \text { Secretario adjunto da comissão administrativa, } \\
\text { encarregado da escrituração }\end{array}$ & $240 \$ 000$ \\
\hline 1 Director & $1: 000 \$ 000$ \\
\hline 1 Primeiro escripturario & $288 \$ 000$ \\
\hline 1 Segundo dito & $180 \$ 000$ \\
\hline 1 Capelão e professor de ensino primário & $300 \$ 000$ \\
\hline 1 Ecónomo & $400 \$ 000$ \\
\hline 1 Ajudante & $200 \$ 000$ \\
\hline 1 Chefe dos guardas & $180 \$ 000$ \\
\hline 11 Guardas & $108 \$ 000$ \\
\hline 1 Medico - gratificação & $100 \$ 000$ \\
\hline 1 Enfermeiro & $216 \$ 000$ \\
\hline 1 Agrónomo, que será o do distrito - gratificação & $100 \$ 000$ \\
\hline 1 Feitor & $216 \$ 000$ \\
\hline 1 Fogueiro maquinista & $324 \$ 000$ \\
\hline 1 Encarregado do observatório e telegrafo & $216 \$ 000$ \\
\hline 1 Cozinheiro & $140 \$ 000$ \\
\hline 1 Ajudante & $100 \$ 000$ \\
\hline
\end{tabular}

Fonte: Diário do Governo, nº 141, de 26 de Junho de 1894.

Este mapa de pessoal evidencia a importância que as questões agrícolas iam assumir no processo de regeneração dos menores (Agrónomo, Feitor, etc.) com vista à sua futura reabilitação social através da aprendizagem de uma atividade profissional. O necessário acompanhamento moral era desenvolvido por todas as categorias incluídas na tabela, com especial destaque para o diretor, o professor, o capelão, o médico e os guardas. Deste modo pode ler-se que "todos os empregados farão diligencia por se tornarem bemquistos dos colonos e seus guias e bons conselheiros"21. A conduta dos funcionários, só por si, devia constituir uma forma de reeducação dos menores com comportamentos desviantes.

De acordo com o regulamento provisório de 1895, os menores que podiam ser admitidos nesta instituição eram os seguintes: vadios ou mendigos "postos à disposição do governo nos termos da lei penal”; «Os menores, que, nos termos

\footnotetext{
${ }^{21}$ Regulamento Geral (provisório) da escola agrícola de Villa Fernando. Diário do governo, $\mathrm{n}^{\mathrm{o}} 174$ de 6 de agosto de 1895 .
} 
da mesma lei, forem isentos de responsabilidade criminal em rasão da idade ou da falta de discernimento e não sejam entregues a seus paes ou tutores"; « Os expostos, abandonados e desvalidos a cargo dos corpos ou corporações administrativas; e, por fim, os menores "desobedientes e incorrigiveis, cuja admissão tiver sido requerida pelos pais ou tutores e autorizada pela lei civil22.

A 6 de outubro de 1895, a Escola Agrícola de Vila Fernando recebia os primeiros menores (51) "todos cadastrados, saídos dos calabouços de Lisboa" ${ }^{23}$. Estes menores, antes de chegar à Escola de Vila Fernando, encontravam-se no mesmo espaço de adultos criminosos. A sua institucionalização constituiu o resultado da articulação de um conjunto de circunstâncias. Em primeiro lugar, a origem dos colonos encontrava-se associada a contextos de pobreza que, muitas vezes, os obrigavam a tornarem-se aliados do crime, da vadiagem ou da mendicidade para poderem sobreviver. Em segundo lugar, o meio em que se encontravam inseridos, fruto de deficientes condições socioeconómicas, possibilitava o desenvolvimento de uma moral pouco adequada; por fim, o contexto familiar e a inexistência de um ambiente educativo adequados também se encontravam na origem de muitos dos processos de institucionalização que chegaram a Vila Fernando.

A conjugação de todos estes fatores constituíram motivo suficiente para considerar estes indivíduos perigosos, contraventores ou delinquentes e conduzilos, através das malhas da justiça, para as instituições de reeducação de menores e aí se proceder à sua reabilitação social e moral ${ }^{24} \mathrm{~A}$ este propósito Ernesto Leite de Vasconcelos, no começo da centúria de novecentos, constatava que "a grande totalidade dos menores aqui entrados são sentenciados pelo delicto da vadiagem" 25 . Acrescentava, ainda, que um dos problemas mais prementes com que se debatia na instituição era o alcoolismo. A titulo de exemplo, no ano económico de 1903/1904 dos 64 colonos institucionalizados 33 sofriam de problemas com álcool ${ }^{26}$. Afirmava-se, gradualmente, uma retórica de responsabilização da

\footnotetext{
${ }^{22}$ : Diário do Governo, $1895 \ldots$...p.cit.

${ }^{23}$ Monografia da Colónia Correcional de Vila Fernando (1931), Lisboa: Typografia do Reformatório Central de Lisboa "Padre António Oliveira".
}

${ }^{24}$ SANTO, J. M. (2000). "Crianças malfeitoras" a contas com a justiça - Os menores catalogados pelo Refugio da Tutoria Central da infância da Comarca de Lisboa 1920-1930. Lisboa: Dissertação de Mestrado apresentada à Universidade de Lisboa.

${ }^{25}$ VASCONCELOS, E. L. (1905). Colónia Agrícola de Vila Fernando - Relatório do Ano Económico de 1903-1904, Porto: Tipografia Real da Oficina de S. José, pp. 26.

\footnotetext{
${ }^{26}$ Em 1921 Manuel Lima Barreto afirmava que, fruto de investigações realizadas, as quatro causas maiores de institucionalização aconteciam por furto, vadiagem, fugas, ofensas corporais, arruaças e distúrbios, prostituição ou ainda desobediência à família e às autoridades (BARRETO, M. L.
} 
família pela produção de maus hábitos, costumes e/ou da própria delinquência ${ }^{27}$. Decorrente destas causas, a necessidade de institucionalizar tornava-se urgente de modo a recolher e regenerar aqueles indivíduos que podiam constituir um perigo para a ordem pública. A escolha da Escola Agrícola de Vila Fernando parece ter sido baseada em dois motivos: por um lado, a zona de inserção da própria escola no espaço rural que era considerado "naturalmente" regenerador; por outro lado, e em articulação com o aspeto anterior, o afastamento do núcleo urbano lisboeta associado ao vicio, ao crime e a contextos morais duvidosos.

Em 1898 a instituição, que até aí se encontrava na dependência do Ministério do Reino, transitou para o Ministério da Justiça. Esta transição assumia um caráter institucional de matriz penitenciária e constituiu um primeiro passo para a alteração da designação de Escola Agrícola de Vila Fernando para Colónia Agrícola Correcional. Esta alteração objetivou-se através da publicação de um novo regulamento que substituiria o anterior datado de 1895. O Decreto Lei de 17 de Agosto de 1901 não deixava dúvidas quanto ao que agora se pretendia desta instituição:

"O caracter do estabelecimento deve ser o de um estabelecimento repressivo. A denominação simples de Escola Agrícola compete aos estabelecimentos de puro ensino(...); este, porem, tem de, pela sua própria legenda, severa e suggestiva, ser intimidação para os menores, e não esperança de fácil realização para os paes que se desoneram do encargo de educar seus fi- lhos, esperando que o Estado os internará numa simples escola, onde os irão buscar quando attinjam a maioridade" 28 .

Este modelo correcional assentava no binómio recompensa/castigo ou vigilância/punição que foi aplicado nas primeiras décadas do século XX em Vila Fernando. No entanto, e à medida que se avançava na centúria de novecentos, percebe-se que as questões educativas ganharam maior expressão no processo de regeneração dos menores. É por isso que logo em 1901, no regulamento institucional, se valorizam as questões de natureza moral que seriam mais "profícuas" com a necessária educação cívica.

A liderança da instituição nas primeiras décadas de vida foi assumida por Ernesto Leite de Vasconcelos. Formado em direito, pela Universidade de Coimbra (1892), foi ele o grande impulsionador da obra que dirigiu até ao ano de 1914

(1921). Relatório de uma missão dos serviços de protecção a menores - algumas notas sobre a assistência a menores delinquentes, Caxias: Tip. Da Escola central de Reforma, pp. 45).

${ }^{27}$ VASCONCELOS, E. L. (1905). Colónia Agrícola de Vila Fernando - Relatório do Ano Económico de 1903-1904, Porto: Tipografia Real da Oficina de S. José, pp. 28.

${ }^{28}$ Decreto-Lei de 17 de Agosto de 1901. 
continuando, mesmo depois da saída, a contribuir com diversos donativos para a instituição de prémios com o objetivo de valorizar os internados. No período em que foi diretor, desenvolveu a herdade de Vila Fernando através dos seus colonos que trabalhavam a agricultura e foi capaz de publicar o primeiro número de um periódico produzido naquela instituição pelos menores ali internados ${ }^{29}$. De acordo com Ernesto Leite Vasconcelos a Colónia de Vila Fernando deveria apresentar-se socialmente como "uma clareira aberta na tenebrosa montanha do crime" $" 30$.

Este homem viu cair o regime monárquico e nascer o regime republicano português (1910). A 1 a República traria importantes avanços, pelo menos do ponto de vista legal, no que respeita aos processos de proteção à infância e jovens em risco. Passados alguns meses da proclamação do novo regime em Portugal, o governo publicou a Lei de Proteção à Infância ${ }^{31}$ que criava as Tutorias da Infância e classificava os menores em diferentes categorias (indisciplinados, ociosos e vadios, incorrigiveis, etc...).

A partir de 1914 a direção da instituição de Vila Fernando conheceu outro diretor - embora interinamente, tornando-se mais tarde definitiva - que manteve, no essencial, a política de regeneração afirmando a importância da educação, da disciplina e do trabalho agrícola e industrial como os principais aspetos capazes de regenerar os menores. Henrique Caldeira Queiroz dirigiu a instituição até à década de 40 do século XX transitando entre paradigmas políticos (República e "Estado Novo"). A sua formação realizou-se na Escola Médico-cirúrgica da cidade do Porto. Exerceu funções como médico municipal em Borba e Ponte de Sôr (Alentejo). Possuía uma experiência política alargada e chegou a ser em 1913 diretor interino da Penitenciária de Lisboa. Em 1915 assumia a direção da Colónia de Vila Fernando ${ }^{32}$ até ao começo da década de 40 do século XX.

Foi sob a atenta observação e ação destes dois diretores que a instituição ao longo de várias décadas cumpriria a sua função corretiva e regeneradora. Como já referimos, à medida que se avançava na centúria de novecentos assumia-se, cada

${ }^{29}$ Cf. Henriques, H. \& Vilhena, C. (2013). "Imprensa e Regeneração de Menores Delinquentes: A Colónia Agrícola de Vila Fernando (1 $1^{a}$ metade do Sé. XX)”. In HERNADEZ DIAZ, J. M. Prensa Pedagógica y Patrimonio Histórico Educativo. Salamanca: Aquilafuente, pp. 245-256.

${ }^{30}$ VASCONCELOS, E. L. (1905). Colónia Agrícola de Vila Fernando - Relatório do Ano Económico de 1903-1904, Porto: Tipografia Real da Oficina de S. José.

${ }^{31}$ Lei de Proteção à infância de 27 de Maio de 1911.

${ }^{32}$ Henrique Caldeira Queiroz foi administrador do concelho e presidente da Comissão Administrativa de Ponte de Sor (1910-1911), deputado à Assembleia Nacional Constituinte (1911-1915), senador (1925-1926), chefe de gabinete do ministro do Colónias (1912) e governado civil do distrito de Portalegre (1915) e presidente da Junta de Freguesia de Vila Fernando (1922). 
vez mais, a importância da educação no processo de transformação dos menores internados e reduzia-se a repressão e a coerção, sobretudo física, sobre o individuo. A regeneração devia realizar-se através da formação integral do menor, com uma disciplina apertada e onde tudo deveria ser pensado em função desse processo transformador, com fineza e detalhe, com o objetivo de promover a qualidade e utilidade do individuo em sociedade.

\section{A INSTRUÇÃO/ EDUCAÇÃO NA PRODUÇÃO DE UM "NOVO INDIVIDUO"}

A Colónia de Vila Fernando apresenta-se como um dos primeiros contextos técnico-institucionais em Portugal cujo maior objetivo era a regeneração do menor potencialmente perigoso para a sociedade. É neste sentido que Cláudia Ribeiro refere que o individuo:

"Ao ter consciência de si mesmo, das suas ações e comportamentos, ao regular a sua conduta na perspetiva da vinculação ao poder, o individuo enleia-se conscientemente nas malhas do controlo governativo, assegurado por autoridades e instituições de diversa ordem, criadas para manipular, instrumentalizar e normalizar a conduta" ${ }^{33}$.

$\mathrm{O}$ ato reeducativo, como já tivemos oportunidade de referir anteriormente, constituía o principal desígnio desta instituição. A regeneração do menor devia ser promovida por todos os funcionários que ali exerciam atividade em todos os momentos. Ernesto Leite de Vasconcelos é claro quando refere, citando um autor internacional (Henry Joly), que "«Para se fazer respeitar e amar por uma semelhante população é necessário viver com ella, até á intimidade, para ganhar a confiança de cada um e estar sempre prompto a levantá-lo nos seus desfalecimentos" ${ }^{34}$. É no detalhe, na construção de uma "relação positiva" entre o especialista e/ou trabalhador e o menor que o processo de regeneração deve ser realizado, procurando recuperar o individuo e devolvê-lo à sociedade ${ }^{35}$. Como realça Cláudia Ribeiro:

"A reabilitação que se desejava operar nestes elementos alheios à normalidade obriga ao desenvolvimento de uma série de tecnologias que, aperfeiçoadas, lubrificadas, optimizadas, vão desembocar no plano ultimo do

\footnotetext{
${ }^{33}$ RIBEIRO, C. (2009). Os outros - A casa pia de lisboa como espaço inclusivo da diferença. Tese de Doutoramento. Faculdade de Letras da Universidade do Porto, pp. 53.

${ }^{34}$ VASCONCELOS, E. L. (1905). Colónia Agrícola de Vila Fernando - Relatório do Ano Económico de 1903-1904, Porto: Tipografia Real da Oficina de S. José, pp. 13.

${ }^{35}$ FOUCAULT, M. (2006). Estratégia, Poder - Saber, $2^{\mathrm{a}}$ ed., col. Ditos \& Escritos IV, Rio de Janeiro: Forense Universitária.
} 
controlo maximizado: a conduta da conduta. Por outra palavras, podemos dizer que o individuo é atingido no coração pelo poder público, passando a ter consciência da obediência que deve (...)"36.

É a construção de corpos dóceis que se encontra em causa. O menor considerado perigoso devia submeter-se a um processo de controlo e vigilância que, gradualmente, o tornasse capaz de se autodirigir de acordo com os princípios e valores apropriados. A aquisição desses valores passava pela construção de uma rotina diária totalizante onde se evidenciava a preparação profissional, moral e literária/intelectual. A preparação profissional dos menores era objetivada através da aprendizagem prática de um oficio. Além dessa aprendizagem, os menores podiam prestar outro tipo de serviços de forma a auxiliar os funcionários nas mais diversas tarefas (secretaria, armazéns, manutenção e reparação de equipamentos, limpeza, recuperação de jardins e edifícios, etc...). Da sua rotina fazia ainda parte a recolha e o cuidar da roupa suja. O serviço de lavandaria era realizado por turnos pelos colonos substituindo-se muitas vezes a possíveis contratações fora da instituição. Do ponto de vista moral, exigia-se aos menores espirito de resignação, respeitos pelos superiores e a apropriação de valores relacionados com a "bondade" e a ajuda ao próximo.

O processo de regeneração dos menores acontecia muito por via de uma "formação total", chave mestra para a devolução, com utilidade, dos menores à sociedade. Henrique Caldeira Queiroz, em 1925, vai ao encontro da consideração anterior quando se refere à importância da transformação do menor:

"Se é certo que o internamento na Colónia representa um castigo - não tenhamos ilusões a tal respeito - não é menos certo que, a par, se pretende modificar, endireitar o que nasceu torto, e educar incutindo ideias, princípios e hábitos por completo diferentes do que constituía a bagagem dos internados à sua entrada na Colónia" ${ }^{37}$.

O diretor assume que este processo de modificação se podia fazer principalmente pela educação. É perentório quando diz:

"Essa modificação, essa educação, não surge, não se faz espontaneamente, automaticamente. É necessário haver quem provoque, quem encaminhe, quem dirija. Salta aos olhos que esse papel, essa alta missão, pertence naturalmente aos indivíduos que mais de perto lidam com os internados, que mais tempo estão em contacto com eles, visto que essa acção só pode ser proveitosa quando continua, persistente, tendente principalmente mais

\footnotetext{
${ }^{36}$ RIBEIRO, C. (2009). Os outros...op.cit., pp. 53.

37 "Ordem de Serviço n ${ }^{\circ}$ 60, de 1925" In Monografia da Colónia Correcional de Vila Fernando (1931), Lisboa: Typografia do Reformatório Central de Lisboa "Padre António Oliveira", pp. 13.
} 
a evitar e prevenir a prática de actos merecedores de castigos do que a castigá-los"38

Defende que é nos processos formativos e/ou educativos que regeneração deveria assentar. No mesmo sentido, alguns anos antes, Ernesto Leite de Vasconcelos referia a importância da educação na Colónia quando realçava que "a educação é, portanto, mais do que uma obra individual" tornando-se necessário que "(...) irradie do educador para os educandos(...)"39.

A formação moral do individuo constituía outra pedra angular no ato reeducativo na medida em que este processo de "purificação" deveria encontrar-se presente em todos os momentos de vigilância e de ação do menor. Henrique Caldeira Queiroz, numa alusão à defesa de uma moral adequada para os menores, salientava a importância de:

"modelar a alma, modificá-la, transformá-la, apagando-lhes até aos últimos vestígios as más impressões que do exterior tenham trazido, substituindo-as por impressões morais de tal forma indicadas que não seja fácil destrui-las (...) a noção de bondade; a de tolerância; a de dignidade; a de amor pela família; a de amor pela Pátria; e tantas outras devem ser os temas proferidos por eles" ${ }^{40}$.

A moralidade era desenvolvida através de um sistema de vigilância que provocava a recompensa e/ou o castigo. A todos os funcionários cabia essa "alta missão" de estar atento a todos os comportamentos dos menores informando o diretor das suas ações. Ao diretor, ouvidos o agrónomo, o médico, o professor e o capelão, cabia recompensar ou castigar os menores institucionalizados pelas suas ações.

Este processo de recompensa-castigo encontrava-se já previsto em 1895 no regulamento provisório da instituição. A recompensa ou a punição dos menores deveria ter em conta a sua avaliação por parte daqueles que assumiam essa responsabilidade. No final de cada mês o diretor mandava publicar internamente "as notas referentes ao aproveitamento de cada um"41. Em função desta classificação, apurados os resultados mensais, o nome daquele que melhor representava os padrões da normalidade seria inscrito num quadro de honra e seriam atribuídas responsabilidades ao menor pelo bom desempenho. Por outro lado, quando o menor não era avaliado positivamente esperava-o uma pena a cumprir. Essa pena

\footnotetext{
${ }^{38}$ Idem.

${ }^{39}$ VASCONCELOS, E. L. (1905). Colónia Agrícola de Vila Fernando - Relatório do Ano Económico de 1903-1904, Porto: Tipografia Real da Oficina de S. José, pp. 9.

${ }^{40}$ Ordem de serviço $\mathrm{n}^{\circ} 60$ de 1925 ...op.cit.

${ }^{41}$ Diário do Governo, 01 de Agosto de 1895, pp. 656.
} 
podia ser muita diversificada e adaptada às diferentes situações em causa. Entre elas destacamos a exoneração de eventuais cargos de confiança atribuídos pelo bom desempenho anterior; a censura particular; a censura pública; a proibição do recreio; separação da comunidade no refeitório, no trabalho e no recreio; a inscrição do seu nome no quadro das condenações e, em extremo, a prisão ou expulsão da Colónia. Este ultimo poder disciplinar cabia apenas ao diretor.

A título de exemplo, no inicio do século XX, as principais faltas cometidas pelos menores institucionalizados eram as seguintes: agressões entre os colonos; agressões com leves ferimentos; fugas e tentativas de fuga; injurias; faltas ao trabalho; furtos de fruta; estragos na roupa; desobediências; entre outras infrações de natureza disciplinar cometidas. Em resposta a estas infrações foram aplicados, entre outros, os seguintes castigos: admoestações; repreensões; privações do recreio e prisão. Este processo regenerador (recompensa-castigo) estava presente em todos os momentos ${ }^{42} \mathrm{e}$ em todo o contexto técnico-institucional procurandose, essencialmente, a fragilidade e a fraqueza do menor, isto é os seus defeitos para poder agir através da punição ${ }^{43}$.

Ilustração 3. A lavoura nas primeiras décadas do Século $X X^{44}$

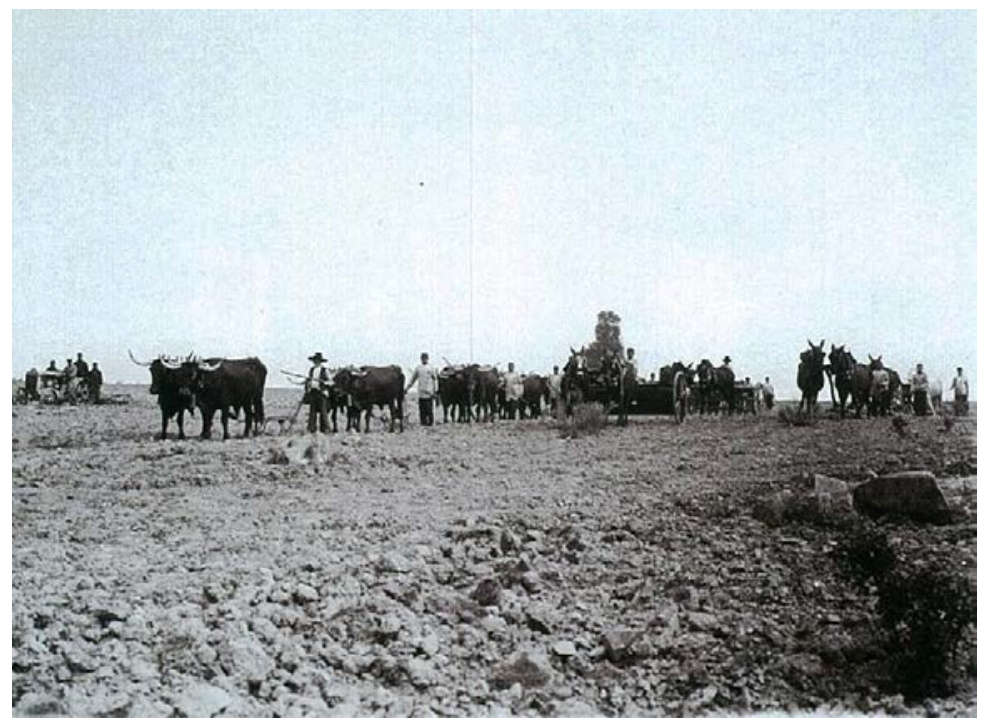

\footnotetext{
${ }^{42}$ VASCONCELOS, E. L. (1905). Colónia Agrícola de Vila Fernando - Relatório do Ano Económico de 1903-1904, Porto: Tipografia Real da Oficina de S. José, pp. 52.

${ }^{43}$ Cf. FOUCAULT, M. (2006). Vigiar e Punir - História da Violência nas Prisões, $31^{\mathrm{a}}$ edição, Petrópolis: Editora Vozes.

${ }^{44}$ BANDEIRA, F. et al. (2009). Arquitectura ...op.cit., pp. 272.
} 
Ilustração 4. Oficina de serralharia da Colónia de Vila Fernando (anos 30, século XX)45

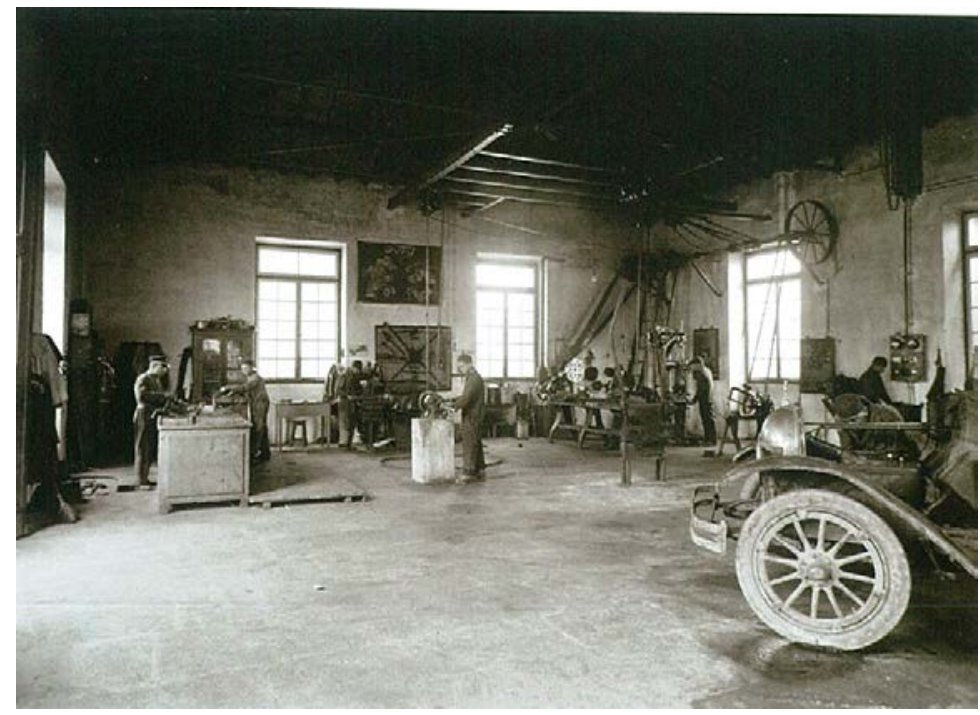

Pelo contrário, os processos educativos procuravam potenciar as virtudes do menor e, desta forma, promover a sua regeneração social. Na Colónia de Vila Fernando os menores tinham aulas de instrução primária distribuídas inicialmente pelo Capelão e pelo professor/ perceptor. Procurava-se aperfeiçoar o individuo através de aprendizagens que, no seu futuro, constituiriam ferramentas essenciais para um processo mais facilitado de integração social. De acordo com esta perspetiva, tentava-se combater o analfabetismo e orientar esta "educação intelectual" para o seu futuro desempenho profissional no domínio da agricultura ou dos ofícios ali ensinados. É por isso que, entre outras disciplinas, era proporcionado aos menores a aprendizagem de desenho linear e geométrico uma vez que "é de reconhecida precisão para os operários em geral e sobretudo para os que seguem algumas das artes que se ensinam na colónia"46.

Além do referido, a regeneração moral dos menores também passava pela dimensão artística. Na Colónia "havia uma grande preocupação da influência moral pela arte" de forma a "levar os espíritos para a contemplação pura, arredandoos assim suavemente, docemente das ideias obsessivas do mal e fazendo com que a sua atenção se fixe em pontos e em ideias mais uteis para a formação de bons

\footnotetext{
${ }^{45}$ BANDEIRA, F. et al. (2009). Arquitectura de...op.cit, pp. 271.

${ }^{46}$ VASCONCELOS, E. L. (1905). Colónia...op.cit, pp. 18.
} 
sentimentos" ${ }^{\prime 7}$. Esta influência, pela arte, constituía um mecanismo auxiliar do processo de transformação global do menor.

Ao longo do século XX a Colónia possuiu grupos de teatro e/ou bandas musicais que serviam para ir mostrando à sociedade a transformação dos menores e a sua utilidade, sobretudo quando faziam concertos e peças de teatro fora da Colónia ${ }^{48}$. No decorrer da primeira metade de novecentos foram muitos os Colonos que integraram bandas regimentais e que tiveram percursos na música.

A formação de natureza intelectual, auxiliada pela dimensão artística que referimos, encontrava-se articulada com a importante formação profissional. Ernesto Leite de Vasconcelos afirmava que "o que a instrução tem é [de](...) ser acompanhado simultaneamente d' uma obsessiva educação moral e profissional, enraizando hábito de trabalho"49. A formação profissional na Colónia, objetivada pela dimensão do trabalho, ao longo da primeira metade de novecentos, consistia essencialmente, como já dissemos, na aprendizagem dos trabalhos agrícolas e industriais. No que respeita aos trabalhos agrícolas:

"Os colonos fazem toda a exploração cultural cerealífera e zootécnica, são eles que lavram e semeiam, que colhem e debulham, que pastoreiam e tratam do gado de manada e de estabulação e de todas as demais operações d'este ramo de trabalhos que é o mais importante do estabelecimento"

O mesmo acontecia em relação a outros ofícios ensinados no estabelecimento (alfaiate, sapateiro, serralheiro, entre outros). A formação por via do trabalho era uma das principais vias de regeneração dos menores da Colónia uma vez que o conhecimento de uma atividade permitiria tornar os menores úteis para a sociedade e, consequentemente, integrarem-se no tecido social.

\section{CONSIDERAÇÕES FINAIS}

A Colónia de Vila Fernando foi uma instituição regeneradora de menores internados por via judicial. A localização escolhida, longe da capital portuguesa, no interior de Portugal assumiu, em si mesma, uma opção política que associava a reabilitação dos menores marginais à natureza e às suas potencialidades neste processo reabilitador. Estas crianças e/ou jovens podem ser definidos como aque-

\footnotetext{
${ }^{47}$ VASCONCELOS, E. L. (1905). Colónia ...op.cit, pp. 21.

${ }^{48}$ Sobre este assunto encontramos informação diversificada nos periódicos publicados pela Colónia: Echos do Lar (1910) e Ecos da Colónia (1929 - 1947).

${ }^{49}$ VASCONCELOS, E. L. (1905). Colónia ...op.cit, pp. 19.

${ }^{50}$ Colónia Correccional Agrícola de Vila Fernando - Catálogo dos artigos com que concorre à Exposição Nacional do Rio de Janeiro (1908), Porto: Tipografia Real da Oficina de S. José, pp. 5.
} 
les que têm um percurso divergente do que é proposto por um determinado regime de verdade, apoiado em saberes específicos como o direito ou a medicina ${ }^{51}$ e, por isso, eram considerados marginais. Michel Foucault refere que o anormal/ marginal era entendido, no plano moral, como alguém que não era bom e/ou justo, adequado e aceite socialmente ${ }^{52}$. Assim, a missão da instituição passava, essencialmente, por proporcionar aos internos um conjunto de atividades baseadas no trabalho e na formação que podiam modificar a sua conduta e torná-los úteis para a sociedade.

$\mathrm{O}$ ato reeducativo assumia este processo de transformação do individuo essencialmente através de três componentes articuladas: o trabalho, principalmente em atividades de natureza agrícola e industrial; a formação moral do indivíduo através de um sistema de recompensa-castigo presente em todos os momentos na Colónia de Vila Fernando instituindo uma forte disciplina; e, a formação literária e artística com o objetivo de combater o analfabetismo e canalizar os ímpetos dos menores para atividades que mais tarde podiam servir a sociedade. Em nosso entender estes constituem os alicerces do processo de regeneração nesta instituição e que ao longo das primeiras quatro décadas foram aplicados a mais de dois mil indivíduos ali internados.

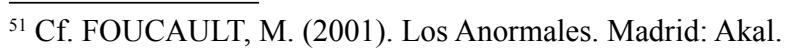

${ }^{52}$ DEL CURA GONZALEZ, M. (2012). ...Op.cit., pp. 60.
} 